\title{
SM Otolaryngology \\ Mutational Analysis of GJB2 Gene in Non-Syndromic Hearing Loss from Patients at Children's Hospital 1- Ho Chi Minh City, Vietnam
}

\author{
Nguyen Dinh ${ }^{1}$, Dung Huu Nguyen ${ }^{2}$, Tran Huyen Lam ${ }^{2}$, Kieu Tho Nguyen ${ }^{2}$, \\ Chuong Dinh Nguyen ${ }^{2}$, Hoang Nguyen ${ }^{3 \star}$, Joseph P Kitzmiller ${ }^{3}$, Vu Anh Hoang ${ }^{4}$, \\ Thuong Chi Bui ${ }^{5}$, Toan Thanh Pham ${ }^{6}$ \\ ${ }^{1}$ Department of Otolaryngology, Children Hospital 1, Vietnam \\ ${ }^{2}$ Department of Otolaryngology, The University of Medicine and Pharmacy at HCM City, Vietnam \\ ${ }^{3}$ Department of Biological Chemistry and Pharmacology, The Ohio State University, USA \\ ${ }^{4}$ The University of Medicine and Pharmacy at HCM City, Center of Molecular and Biomedicine, Vietnam \\ ${ }^{5}$ Department of Obstetrics/Gynecology, The University of Medicine and Pharmacy at HCM City, Vietnam \\ ${ }^{6}$ University of Natural Science, Vietnam
}

\section{Article Information}

Received date: Jul 14, 2017

Accepted date: Jul 26, 2017

Published date: Jul 31, 2017

\section{*Corresponding author}

Hoang Nguyen, The Ohio State University, College of Medicine,

Department of Biological Chemistry and Pharmacology, Columbus, Ohio, USA,

Email: Hoang.Nguyen@osumc.edu

Distributed under Creative Commons CC-BY 4.0

Keywords GJB2 gene; Non-syndromic hearing loss; Congenital sensorineural hearing loss; p.V37I; c.23delC; c.109G>A

Article DOI 10.36876/smotol.1009

\section{Abstract}

Purpose: Hereditary hearing loss is associated with several mutated genes; among them mutant GJB2 is the main cause. We conduct this study to provide initial information about types, rates, and influences of mutations in Vietnamese patients.

Patients and Methods: Genomic DNA is extracted from peripheral blood samples of 96 childhood patients and 100 healthy control subjects. Primers are designed to amplify GJB2 gene, encoding Cx26 protein, followed by detecting mutations with Sanger sequencing technology.

Results: Exon 2 of GJB2 gene was sequenced from all 96 samples. We detected 9 variants of GJB2 gene from 56 patients (c.235delC, c.299_300delAT, c.634T>A, c.79G>A, c.608T>C, c.368C>A, c.11G>A, c.341A>G and $c .109 \mathrm{G}>\mathrm{A}$ ). Of which, c.634T>A is a novel variant expected to be a causing disease mutation. Variants detected in 56 cases create 14 genotypes, including 2 causing disease genotypes (c.235delC and c.79G>A / c.299 300delAT), 7 genotypes with controversial role in disease (c.109G>A; c.11G>A; c.109G>A / c.341A>G; c. $109 \mathrm{G}>\mathrm{A} /$ c.608T>C; c. $109 \mathrm{G}>\mathrm{A} /$ c. $634 \mathrm{~T}>\mathrm{A} ;$ c.79G $>\mathrm{A} /$ c. $109 \mathrm{G}>\mathrm{A} /$ c.341A>G and c.79G $>\mathrm{A} /$ c. $341 \mathrm{~A}>\mathrm{G} /$ c. $368 \mathrm{C}>\mathrm{A}$ ), and 5 genotypes containing benign single nucleotide polymorphisms (c.79G>A; c.608T>C; c.79G $>A$ / c.341A>G; c.79G>A / c.368C>A and c.79G>A / c.341A>G / c.368C>A).

Conclusion: We have detected the types and rate of mutations appearing on protein coding region of GJB2 gene from 96 Non-Syndromic Hearing Loss children. Most of the mutations are missense heterozygous or compound heterozygous and under controversy. We suspect that in Vietnamese population, hereditary hearing loss might be caused by interaction between disturbance of GJB2 and other genes such as GJB6, SLC26A4 or 12S rRNA on mitochondria. Next generation sequencing should be use to clarify multigenic defects of hereditary hearing loss in Vietnamese children.

\section{Introduction}

Hearing loss is the most common sensory deficit in humans with congenital/prelingual deafness affecting 1 in 1000 children [1]. Delays in treatment for profound sensorineural hearing loss will result in the inability for the patient to develop normal spoken speech and language skills [2]. Additionally, candidacy for cochlear implantation, currently the only medical treatment available for the treatment of profound sensorineural hearing loss, cannot be established without a comprehensive medical examination. Hereditary hearing loss has been acknowledged more than 100 years with nonsyndromic and syndromic form [3]. Nonsyndromic form account for approximately $67 \%$ of genetic deafness, whereas a specific syndrome can be identified in about $33 \%$ of cases. It is estimated that more than 70 locus may contribute to nonsyndromic deafness. On non-syndromic hereditary hearing loss, there are common list of genes are: GJB2, GJB3, GJA1, MYO6, SLC26A4, SLC26A4, POU3F4, KCNQ4, COCH and 12s4RNA. Single gene, GJB2 (also known as connexin 26) (mutated on chromosome 13q12), is the most common cause of congenital hereditary deafness in many populations [4]. The GJB2 gene encodes connexin 26, a component of gap junctions. Gap junctions are wide expressed in the cochlea and are thought to participate in the recycling of potassium ions from hair cells to the cochlear endolymph. The GJB2 gene contains the instructions for manufacturing a number of proteins, including Connexin 26. Connexin proteins in general are called "gap-junction proteins" which are necessary for cells to communicate with each other. Without sufficient levels of Connexin 26, the potassium flow from hair cells in the cochlea is disrupted, resulting in extremely high levels of potassium in the Corti's organ, leading to the profound sensorineural hearing loss. 
Mutated variant gene GJB2 are varies at different races, for instance in Caucasian, African American, Middle East Asian, and Indian, mutations variant genes are: c.35delG, p.R143W, c.167delC, c.235delC and p.W24X [5]. Vietnam is one of the country has highest rate of hereditary hearing loss, however due to studies limited and not thorough enough. Dr Nguyen Tuyet Xuong [6] is one of the pioneer geneticist, who did the research on gene GJB2, GJB6 and $12 S$ rRNA with co-pioneer Dr Nguyen Thuy Duong [4] on 76 loci of patients. Due to small sample size patients, this can't reflect all complexicity of all genes within the Vietnam population. Therefore, thorough evaluation study of gene GJB2 will be a best meaningful project. This project will be a big hint for all the prevention, screening, and treatment guidelines of all hereditary hearing loss of children in Vietnam.

\section{Subjectives and Methdodology}

\section{Research subjects}

96 unsyndrome congenital hearing loss patients have been examined and participated at Nhi Dong I Children Hospital, HCM City, Vietnam. We also examined 100 patients who have normal hearing. All patients signed the consents and followed the IRB Review of Vietnam guideline/protocols.

\section{Research methodology}

DNA genomic extraction: For molecular testing, DNA was extracted from $2 \mathrm{ml}$ of peripheral blood samples using standard nonorganic protocols. Bloods were stored with EDTA agent, and transported to Molecular Genetic Institute at HCMU School of Medicine and Pharmacy. Genomic DNA was extracted by using QIAamp DNA kit (Quiagen, USA), followed by manufacturing instruction.

Probe and sequencing primers: Pairs of primer were designed based on primer 3 (http://bioinfo.ut.ee/primer3-0.4.0/). The primers for exon F2 were as follows: (5'-GTCCTAGCTAGTGATTCCTG-3') and exon R2 (5'-GTTGCCTCATCCCTCTCATG-3'), a 803-bp product was obtained after amplification.

The mutation spectrum and prevalence of mutations varies significantly among ethics groups. The p.V37I variation in GJB2 is highly prevalent in East Asian deafness, but there is a controversial relationship between some mutations, including p.V37I (c.109G>A), and the hearing phenotype. In the present study, 96 patients with nonsyndromic sensorineural hearing loss, 56 normal-hearing individuals, and 32 patients were affected with V37I variant.

Table 1: Reaction of PCR and temperature/interval on gen GJB2.

\begin{tabular}{|c|c|c|c|c|c|}
\hline \multicolumn{2}{|l|}{ Reactions } & \multicolumn{4}{|c|}{$\begin{array}{l}\text { Temperature and Interval of probe } \\
\text { PCR }\end{array}$} \\
\hline PCR conducted & Volume $(\mu \mathrm{l})$ & Periods & Temp & Times & Interval \\
\hline 10X PCR buffer & 1.5 & & $98^{\circ} \mathrm{C}$ & 3 mins & \\
\hline $2.5 \mathrm{mM}$ dNTP & 1.5 & Denatured & $98^{\circ} \mathrm{C}$ & $10 \mathrm{sec}$ & \multirow{3}{*}{40} \\
\hline $\begin{array}{c}10 \mu \mathrm{M} \text { primer }\left(\mathrm{F}_{2} \text { and }\right. \\
\left.\mathrm{R}_{2}\right)\end{array}$ & 1.5 & Binding & $58^{\circ} \mathrm{C}$ & $20 \mathrm{sec}$ & \\
\hline $\mathrm{H}_{2} \mathrm{O}$ & 8.4 & Prolonged & $72^{\circ} \mathrm{C}$ & $40 \mathrm{sec}$ & \\
\hline Takara HS Taq & 0.1 & & $72^{\circ} \mathrm{C}$ & 3 mins & \\
\hline gDNA & 2.0 & & & & \\
\hline (Total Volume & 15) & & & & \\
\hline
\end{tabular}

Designed probe primer ASO-PCR based on the replacement of G become A at 109 position, we also switch 3'nucleotide to prevent false positive. At the un-mutated fragment, during probe primer MuR, we have 2 points where gene can't replicate. At the mutated fragment, c.109G $>\mathrm{A}$, there is one point at position 3's, gene still be able to replicate. 152-bp product was obtained after amplification process.

PCR technique: Probe and sequence of PCR products of GJB2 gene is a common approach that has the advantage of detecting most alleles, and done by TaKara Taq HotStart Polymerase (Takara, Japan). PCR was conducted from 58-98 degree Celsius for 10 seconds to 3 minutes for 40 cycling (Table 1).

PCR product were produced in agarose gel $2.0 \%$ with ethidium bromide and observed by camera photographer Geldoc-It (UVP, USA). Finally, PCR Wash buffered by QIAquick Gel Extraction kit (Qiagen, USA) based on the manufacturing instruction.

DNA sequencing: PCR fragments were sequenced using the forward and/or reverse primers and ABI BigDye Terminator v3.1 Cycle Sequencing Kit (Applied Biosystems, Inc., Foster City, CA) and ABI 3130 Genetic Analyzer. Finally, we plugged all data in and analyzed by PolyPhen Software.

Statistical analysis: Experiment Results were analyzed by Excel and IBM SPSS v.20.0 on the p.V37I with 95\% Confident Interval (CI).

\section{Results and Disscussion}

\section{General characteristic of experiments}

Inclusion criteria were: 1) congenital; 2) clinical presentation: non-syndromic HL/no related medical finding; 3) type of hearing loss: sensorineural; 4) prognosis: stable/progressive HL; 5) both ears affected; 6) sporadic case in his/her family; and 7) persons with unaffected parents. Exclusion criteria were: 1) syndromic hearing loss; and 2) congenital hearing loss caused by infections. The period of study took place between the April, 2015 to the September 2016. Participants are based on ages, sex, and severity of hearing loss. Average ages of participants are 4.71, youngest one is 1 year old, and eldest one is 11. Ratio between Male: Female is 1:0.8 (52 male and 44 females) (Table 2).

Table 2: Characteristic of two experiences groups.

\begin{tabular}{|c|c|c|c|c|}
\hline \multirow{2}{*}{$\begin{array}{c}\text { Clinical } \\
\text { characteristic }\end{array}$} & \multicolumn{2}{|c|}{ Affected Patients ( $n=96)$} & \multicolumn{2}{|c|}{ Control group $(n=100)$} \\
\hline & Numbers & Percentage (\%) & Numbers & Percentage (\% \\
\hline \multicolumn{5}{|l|}{ Sex } \\
\hline Male & 52 & 54.16 & 34 & 34 \\
\hline Female & 44 & 45.84 & 66 & 66 \\
\hline \multicolumn{5}{|l|}{ Ages (years) } \\
\hline Average of ages & 4.71 & & 32.18 & \\
\hline Youngest & 1.0 & & 19 & \\
\hline Eldest & 11 & & 65 & \\
\hline \multicolumn{5}{|c|}{ Severity of hereditary hearing loss } \\
\hline Mild & 1 & 1.1 & & \\
\hline Moderate & 5 & 5.2 & & \\
\hline Severe & 13 & 13.5 & & \\
\hline Profound & 77 & 80.2 & & \\
\hline
\end{tabular}

$\mathrm{N}=100$ (control). with the peripheral blood smear. we collect from physicians. nurses. and medical students. whom have normal hearing loss. Average ages for this group is 32.18 (youngest one is 19 and highest one is 65). Ratio Male: Female is $0.51 / 1(34: 66)$. 
Table 3: DNA and Amino Acid Sequence Variation in gene GJB2.

\begin{tabular}{|c|c|c|c|c|c|}
\hline Variation of nucleotide & Amino Acid Sequence Variation & db SNP ID & Quantity & Percent (\%) & Meaning of mutated \\
\hline c. $235 \mathrm{delC}$ & p.L79CfsX3 & rs80338943 & 2 & 2.08 & Pathogenic \\
\hline c.299-300delAT & p.H100RfsX14 & rs111033204 & 1 & 1.04 & Pathogenic \\
\hline c. $634 \mathrm{~T}>\mathrm{A}$ & p.Y212N & New Unmutated & 1 & 1.04 & Unclassified \\
\hline c. $11 \mathrm{G}>\mathrm{A}$ & p.G4D & rs111033222 & 2 & 2.08 & Pathogenic \\
\hline c. $109 \mathrm{G}>\mathrm{A}$ & p.V37I & rs72474224 & 32 & 33.33 & Pathogenic \\
\hline c.79G $>A$ & p.V27I & rs2274084 & 21 & 21.87 & Novel \\
\hline c. $341 \mathrm{~A}>\mathrm{G}$ & p.E114G & rs2274083 & 15 & 16.67 & Novel \\
\hline c. $368 \mathrm{C}>\mathrm{A}$ & p.T123N & rs111033188 & 3 & 3.12 & Novel \\
\hline c. $608 \mathrm{~T}>\mathrm{C}$ & p.1203T & rs76838169 & 3 & 3.12 & Novel \\
\hline
\end{tabular}

DNA and amino acid sequence variations in GJB2 among hearing loss cases

After DNA genomic extraction from 96 patients on GJB2 of protein Cx26. We found 56 cases with variation in gene GJB2, there are 3 cases of loss the nucleotide and 53 cases replacement of the nucleotide (Table 3 ).

GJB2 variants mutated c. 235 delC were detected in approximately $2.08 \%$ ( 2 cases) of individuals with hearing loss in South region of Vietnam (Figure 1A). This number is little lower compared to other countries in Asia such as South Korea (6.8\%) [8], Japan (7.0\%) [9], China (20.3\%) [10], and there is not much different compared to the North Region of Vietnam (3/76, 3.95\%) [4]. Thus, the contribution of GJB2 variants to hearing loss varied between populations. Probably it is depended upon demographic; ethics could lead to mutation variants gene c.235delC differently.

Most patients found homozygous for the c.35delC or p.W24x mutation, which will shorting and cause malfunction of protein $\mathrm{Cx} 26$, then lead to bilateral hearing impairment. Best method treatment for this hereditary hearing loss by wearing implant electronic cholera or hearing aid device [11]. Early detection of mutated gene c.235del will be the best prognosis.

The c.35delC mutation, also known as $30 \mathrm{delC}$, with labeled as 299-300delAT, is predicted to inactivate connexin 26 . The single

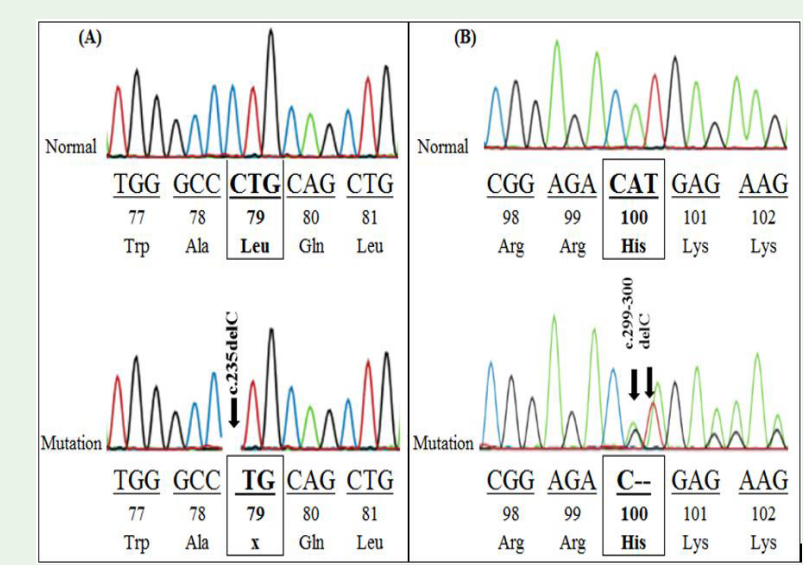

Figure 1: Sequence of GJB2 gene fragments of patients on exchange of nucleotide on exon2 of GJB2 . A) Mutated c.235delC, B) Mutated c.299300delAT. base deletion within a stretch of six Gs between position 100 and 113 , results in a frame shift leading to a UGA stop codon, two residues downstream and premature termination of the connexin 26 synthesis at the $100^{\text {th }}$ amino acid. The c.71G $>$ A (p.W24X) mutation is a nonsense mutation consisting of a T-to-G transition at position 79th. Normally at the 79th, Leucin is supposed to have CTG, however due to mutated gene, we only have TG left (Figure 1A), and so Cx26 protein is shorter than normal. This is the common mutated gene in Asia especially in Korea [12], Japan [9] and Taiwan [13].

There is one patient (1.04\%) with labeled c.T634A (p.Y212N), there is unknown carboxyl in protein $\mathrm{Cx} 26$ which can change the variation of gene GJB2 (Figure 2A). To eliminate the error during probe and sequence of DNA, we repeat again this step on PCR (machine Takara HS Taq); the result is still the same. Later, we use the PolyPhen-2 software to predict any pathogenic of this gene GJB2, result came out this is the pathogenicity gene with score $=1.0$. Tyrosine 212 of protein Cx26 is the best position for all alleles, analyze the function mutated of gene $\mathrm{p} . \mathrm{Y} 212 \mathrm{~N}$ will clarify all the pathogenesis of this experiment.

Variation gene c. $11 \mathrm{G}>\mathrm{A}$, replacement of Glycine at $4^{\text {th }}$ position within protein Cx26 became Aspartic Acid, 2.08\% (2/96) on this experiment. This is based on previous experiment $[13,14]$.

The allele frequency of gene c.109G $>\mathrm{A}$ is found $33.3 \%(32 / 96)$ in children (Figure 2B), majority is heterozygous allele. This is very higher number compare among other Asia population, China (8.86\%)

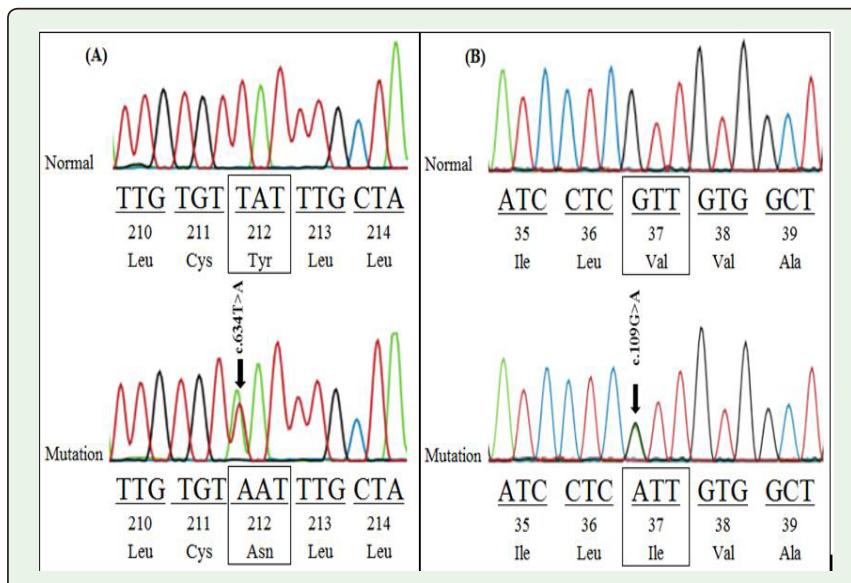

Figure 2: Variation of nucleotide on exon 2 of GJB2. A) Mutated c.634T>A, B) Mutated c.109G >A. 


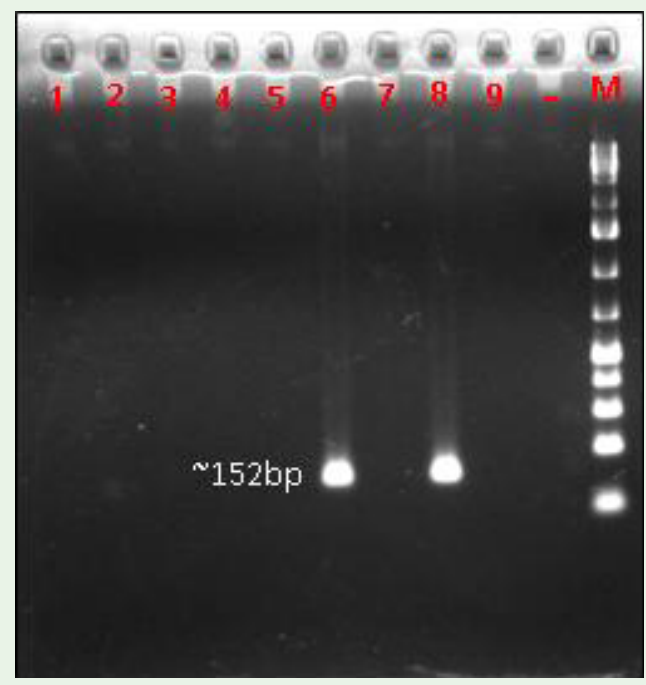

Figure 3: Multiplex breakpoint on ASO-PCR was detected. Water 1,2,3,4,5,7 and 9: no variation. Water 6: variation of p.V37I. Water 8: variation is indicated. M: Control DNA.

[15], Korea (19.4\%) [16], Japan (16.5\%) [17], and especially in South East Asia such as Thailand (11.1\%) [18], Malaysia (62\%) [19], and Vietnam (17.1\%) [4]. At the beginning of this experiment, variation of gene GJB2 were not found in gene c.109G $>A$, later c.109G $>A$ is found more on heterozygous or homozygous, thus pathogenic of allele are warranted [16,20-23].

The p.V37I is another GJB2 variant that is frequently found in East Asian Population. The variant resides in transmembrane M1 domain in beta connexins. The p.V37I variant has been frequently observed to be associated with mild to moderate hearing loss. At the position $37^{\text {th }}$ of protein Cx26, Valine is considered as the most preservable amino acid [24]. Functional studies of electrical conductance between paired Xenopus oocytes demonstrated that the p.V37I mutant protein is non-functional, implying that the variant is pathogenic mutation, but it is not severe as c.235delC or c.2990delAT $[11,12,16]$.

Table 4: List of Identified Mutations after the Sequencing of GJB2 identified in the Hearing Impaired Vietnam Children.

\begin{tabular}{|c|c|c|c|c|}
\hline Genotype & Variation on protein Cx26 & State & Deafness degree & No of cases \\
\hline c. $235 \mathrm{delC}$ & p.L79CfsX3 & Homozygote & Profound & 2 \\
\hline c.79G>A+c.299-300delAT & p.V27I+p.H100RfsX14 & Heterozygote & Profound & 1 \\
\hline c. $11 \mathrm{G}>\mathrm{A}$ & p.G4D & Heterozygote & Profound & 2 \\
\hline \multirow{5}{*}{ c. $109 \mathrm{G}>\mathrm{A}$} & \multirow{5}{*}{ p.V37I } & Homozygote & Mild & 1 \\
\hline & & Homozygote & Mild & 1 \\
\hline & & Heterozygote & Severe & 2 \\
\hline & & Homozygote & \multirow{2}{*}{ Profound } & 1 \\
\hline & & Heterozygote & & 21 \\
\hline c. $109 \mathrm{G}>\mathrm{A}+\mathrm{c} .341 \mathrm{~A}>\mathrm{G}$ & p.V37I+p.E114G & Heterozygote & Profound & 1 \\
\hline \multirow{2}{*}{ c. $109 \mathrm{G}>\mathrm{A}+\mathrm{c} .608 \mathrm{~T}>\mathrm{C}$} & \multirow{2}{*}{ p.V37I+p.I203T } & Heterozygote & Severe & 1 \\
\hline & & Heterozygote & Profound & 1 \\
\hline c. $109 \mathrm{G}>\mathrm{A}+\mathrm{c} .634 \mathrm{~T}>\mathrm{A}$ & p.V37I+p.Y212N & Heterozygote & Mild & 1 \\
\hline c. $79 G>A+c .109 G>A+c .341 A>G$ & p.V27I+ p.V37I+p.E114G & Heterozygote & Profound & 1 \\
\hline c. $79 G>A+c .109 G>A+c .368 C>A$ & p.V27I+ p.V37I+p.T123N & Heterozygote & Profound & 1 \\
\hline c. $608 \mathrm{~T}>\mathrm{C}$ & p.I203T & Heterozygote & Profound & 1 \\
\hline \multirow{2}{*}{ c.79G $>A$} & \multirow{2}{*}{ p.V27I } & Homozygote & \multirow{2}{*}{ Profound } & 1 \\
\hline & & Heterozygote & & 3 \\
\hline c. $79 G>A+c .341 A>G$ & p.V27I+p.E114G & Heterozygote & Profound & 12 \\
\hline c. $79 \mathrm{G}>\mathrm{A}+\mathrm{c} .368 \mathrm{C}>\mathrm{A}$ & p.V27I+p.T123N & Heterozygote & Profound & 1 \\
\hline c. $79 G>A+c .341 A>G+c .368 C>A$ & p.V27I+ p.E114G+p.T123N & Heterozygote & Profound & 1 \\
\hline Normal & - & - & - & 40 \\
\hline
\end{tabular}

Citation: Dinh N, Nguyen DH, Lam TH, Nguyen KT, Nguyen CD, Nguyen H, et al. Mutational Analysis of GJB2 Gene in Non-Syndromic Hearing Loss from Patients at Children's Hospital 1- Ho Chi Minh City, Vietnam. SM Otolaryngol. 2017; 1(2): 1009.

https://dx.doi.org/10.36876/smotol.1009
We started to observe the variation of p.V37I on the normal hearing patients with ASO-PCR technique, with the special probe at 58 degree Celsic. To eliminate for false positive result, we conducted experiments with water DNA, positive DNA variation confirmed p.V37I. PCR products were conducted with agarose gel 2.0\%. A 152bp band indicative of amplification of the Del, breakpoint junction (Figure 3). Within 100 sample of water by ASO-PCR, 15\% $(15 / 100)$ of patients were normal variation c.109A $>$ A. This statistical significant different between disease group (33.3\%) vs. negative group $(15 \%), p$ value $=0.03$

Probably this is pathogenicity variant; however, it is depended upon other factors such as environment or genetic factors [25], or protein connexein related, which play important role of gene GJB2 variation p.V37I [18]. Thus, maybe within 23 cases, c.109A $>A$, heterozygous alleles have others variants of GJB6.

We also found that replacement of amino acid p.V27I, p.E114G, p.T123N and p.I203T on area code of gene GJB2, were previously found non-pathogenic. And, variation p.V27I has highest frequency $37.5 \%$ among all the variations.

\section{Contribution of variation of genotype GJB2 and hearing loss}

We detected 14 variants of GJB2 gene from 96 patients. There are two variants confirmed to be pathogenic and caused very profound degree of deafness. Seven variants gene (c.109G $>A$; c.11G $>A$; c.109G $>$ A/c.341A $>$ G; c.109G $>A / c .608 T>C ; \quad$ c.109G $>A / c .634 T>A ;$ c.79G $>\mathrm{A} / \mathrm{c} .109 \mathrm{G}>\mathrm{A} / \mathrm{c} .341 \mathrm{~A}>\mathrm{A}$ and c.79G $>\mathrm{A} / \mathrm{c} .341 \mathrm{~A}>\mathrm{G} / \mathrm{c} .368 \mathrm{C}>\mathrm{A})$ are variant expected to be a causing disease mutation. 5 variants (c.79G $>$ A; c.608T $>$ C; c.79G $>A / c .341 \mathrm{~A}>\mathrm{G} / \mathrm{c} .368 \mathrm{C}>\mathrm{A}$ and c.79G $>\mathrm{A} /$ c. $341 \mathrm{~A}>\mathrm{G} / \mathrm{c} .368 \mathrm{C}>\mathrm{A})$ are confirmed as polymorphism nucleotide (SNP) non-pathogenic. Higher percent $(89.28 \%, 50 / 56$ cases) are identified within state of homozygote or heterozygote, only smaller percent $(10.72 \%, 6 / 56$ cases $)$ are identified within state of homozygote (Table 4). 
There are 6/32 cases have variants gene c.109A $>\mathrm{G}$ ( 3 homozygote and 29 heterozygote), the rest are considered non-pathogenic mutated. In the East Asian population, two variants, p.V27I (c.79G $>A$ ) and p.E114G(c.3.41G>A), are considered benign polymorphisms since these variants have been identified in both hearing loss patients and normal hearing control. However, some studies in Thailand [26], and North America [27] have postulated that homozygote carrying both p.V27I and p.E114G variants could cause hearing loss. P.V27I means there is a substitution of valine for isoleucin in codon 27, c.79G $>$ A) and p.E114G means there is a substitution of glutamic acid for glycine in codon 114, c.344A $>$ G. These two variant are the most common variants cause higher percent (23.21\%) (13/26 cases) of the impairing of hearing loss. Exceptionally, these two variants don't cause any hearing loss pathogenicity in Turkey population [28]. Previously studies on construction of CX26 variants and transfection of HEK 293 Cells. HEK293 cell line is used widely for gap junction (GJ) studies, the results of these previous in vitro cell-based assays studies indicated that $\mathrm{VG}^{*}$ and $\mathrm{I}^{\star} \mathrm{G}^{*}$ halotypes of GJB2 may play a role as pathogenic variants' in hereditary hearing impairment [29].

\section{Discussion}

There are 6 cases carries 3 variant gene $(c .608 \mathrm{~T}>\mathrm{C}, \mathrm{c} .79 \mathrm{G}>\mathrm{A}$ and c.79G $>$ A/c.368C $>$ A), are considered not related to cause any impair hearing loss. There are 40 cases; we did not find any variations on gene GJB2. All 46 patients were diagnosed as hereditary hearing loss from severe to profound state. It is hard to explain the cause of it; it could be due to genetic factors or nature of its gene. Sanger sequencing technique is little bit challenge for us, because it only allows us to analyze individual fragment. Given the need for precise sequence analysis in a clinical diagnostic laboratory, use of this fragment analysis technique should be considered as traditional method. Hopefully, there should be a yet powerful technique would provide us additional information that improves data interpretation over sequence analysis.

\section{Conclusion}

In summary, 6/56 (10.71\%) cases within total 96 cases, we found variants of the GJB2 gene of known clinical significance in Vietnam with congenital NSHL. These most prevalent mutations are c.23delC and c.299_300delAT, which caused the degree of hearing loss from severe to profound form. Variant c.109G $>$ A has the highest prevalent among all other variants. For those patients diagnosed with congenital NSHL but unfound variant gene GJB2, next generation sequencing technique should be used to identify the defects of other related gene. This will be the root solution to confirm diagnosis with better treatment.

\section{Acknowledgements}

The authors are grateful to all medical staffs, statistician for assistance with data analysis. The authors are grateful for the assistance and expertise in laboratory analysis of the laboratory staff of Department of Otolaryngology, Children Hospital 1, HCM City, Vietnam; The University of Natural Science, Department of Biochemistry, HCM City, Vietnam; The Center of Molecular and Biomedicine, The Department of Otolaryngology, and the Department of Obstetrics/Gynecology, of The University of Medicine and Pharmacy at HCM City, HCM City, Vietnam. Special thanks to scientists and professors at The Ohio State University, College of
Medicine, Department of Biological Chemistry and Pharmacology, Columbus, Ohio, USA for re-evaluate, recommend and validate important basic intellectual concepts correlate to clinical. The authors are also thankful for the oversight of all aspects of this research but the Internal Review Boards (IRB) in Vietnam, as well as Department of Public Health, Board of Medicine in Vietnam.

\section{References}

1. Berg AL, Spitzer JB, Towers HM, Bartosiewicz C, Diamond BE. Newborn hearing screening in the NICU: profile of failed auditory brainstem response/ passed otoacoustic emission. Pediatrics. 2005; 116: 933-938.

2. Declau F, Boudewyns A, Van den Ende J, Peeters A, van den Heyning $P$. Etiologic and audiologic evaluations after universal neonatal hearing screening: analysis of 170 referred neonates. Pediatrics. 2008; 121: 1119_ 1126.

3. Nejat Mahdieh BR. Genetics of hearing loss. Semin Hear. 2000; 21: 212-246.

4. Duong NT, Xuan NT, Ha NH, Ton ND, Hue HTT, Trang PTT, et al. Mutational analysis of GJB2, GJB6 and 12S rRNA genes in Vietnamese non-syndromic deaf children. Asian J Biomed Pharm Sci. 2015; 5: 1-7.

5. Mahdieh N, Rabbani B, Wiley S, Akbari MT, Zeinali S. Genetic causes of nonsyndromic hearing loss in Iran in comparison with other populations. J Hum Genet. 2010; 55: 639-648.

6. Xương NT. Study on the charactristics and risk factors of hearing impairment of children from 2-5 years old of the elementary schools at downtown of Hanoi City, Vietnam. Vietnam National Immunology Institute. 2014.

7. Liu J, Huang S, Sun M, Liu S, Liu Y, Wang W, et al. An improved allele-specific PCR primer design method for SNP marker analysis and its application. Plant Methods. 2012; 8: 34

8. Lee KY, Choi SY, Bae JW, Kim S, Chung KW, Drayna D, et al. Molecular analysis of the GJB2, GJB6 and SLC26A4 genes in Korean Deafness Patients. J Pediatr. 2009; 72: 1301-1309.

9. Tsukada K, Nishio S, Usami S. A large cohort study of GJB2 mutations in Japanese hearing loss patients. Clin Genet. 2010; 78: 464-470.

10. Liu XZ, Xia XJ, Ke XM, Ouyang XM, Du LL, Liu YH, et al. The prevalence of connexin 26 (GJB2) mutations in the Chinese population. Hum Genet. 2002;111: 394-397.

11. Matsushiro N, Doi K, Fuse $\mathrm{Y}$, Nagai K, Yamamoto $\mathrm{K}$, Iwaki $\mathrm{T}$, et al. Successful cochlear implantation in prelingual profound deafness resulting from the common 233delC mutation of the GJB2 gene in the Japanese. Laryngoscope. 2002; 112: 255-261.

12. Park HJ, Hahn SH, Chun YM, Park K, Kim HN. Connexin26 mutations associated with nonsyndromic hearing loss. Laryngoscope. 2000; 110: 1535-1538.

13. Hwa HL, Ko TM, Hsu CJ, Huang CH, Chiang YL, Oong JL, et al. Mutation spectrum of the connexin 26 (GJB2) gene in Taiwanese patients with prelingual deafness. Genet Med. 2003; 5: 161-165.

14. Xin F, Yuan Y, Deng X, Han M, Wang G, Zhao J, et al. Genetic mutations in nonsyndromic deafness patients of Chinese minority and Han ethnicities in Yunnan, China. J Transl Med. 2013;11: 312.

15. Zheng J, Ying Z, Cai Z, Sun D, He Z, Gao Y, et al. GJB2 mutation spectrum and genotype-phenotype correlation in 1067 Han Chinese subjects with nonsyndromic hearing loss. PLoS One. 2015; 10: 1-12.

16. Kim SY, Park G, Han KH, Kim A, Koo JW, Chang SO, et al. Prevalence of p.V37I Variant of GJB2 in Mild or Moderate Hearing Loss in a Pediatric Population and the Interpretation of Its Pathogenicity. PLoS One. 2013; 8: e61592.

17. Abe S, Usami S, Shinkawa H, Kelley PM, Kimberling WJ. Prevalent connexin 26 gene (GJB2) mutations in Japanese. J Med Genet. 2000; 37: 41-43. 
18. Wattanasirichaigoon D, Limwongse C, Jariengprasert C, Yenchitsomanus PT, Tocharoenthanaphol C, Thongnoppakhun W, et al. High prevalence of V37I genetic variant in the connexin-26 (GJB2) gene among non-syndromic hearing-impaired and control Thai individuals. Clin Genet. 2004; 66: 452-460.

19. Ruszymah BHI, Wahida IF, Zakinah Y, Zahari Z, Norazlinda MD, Saim L, et al. Congenital deafness: High prevalence of a V37I mutation in the GJB2 gene among deaf school children in Alor Setar. Med J Malaysia. 2005; 60 269-274.

20. Kelley PM, Harris DJ, Comer BC, Askew JW, Fowler T, Smith SD, et al. Nove mutations in the connexin 26 gene (GJB2) that cause autosomal recessive (DFNB1) hearing loss. Am J Hum Genet. 1998; 62: 792-799.

21. Huang $Y$, Yang $X$, Chen W, Duan $B$, Lu P, Wang $Y$, et al. Prevalence of $p$. V37I variant of GJB2 among Chinese infants with mild or moderate hearing loss. 2015; 8: 21674-21678.

22. Li L, Lu J, Tao Z, Huang Q, Chai Y, Li X, et al. The p.V37I exclusive genotype of GJB2: A genetic risk-indicator of postnatal permanent childhood hearing impairment. PLoS One. 2012; 7: 7-10

23. Huang S, Huang B, Wang G, Yuan Y, Dai P. The Relationship between the p.V37I Mutation in GJB2 and Hearing Phenotypes in Chinese Individuals. PLoS One. 2015; 10: e0129662.
24. Palmada M, Schmalisch K, Böhmer C, Schug N, Pfister M, Lang F, et al. Loss of function mutations of the GJB2 gene detected in patients with DFNB1associated hearing impairment. Neurobiol Dis. 2016; 22: 112-118.

25. Bruzzone R, Veronesi V, Gomès D, Bicego M, Duval N, Marlin S, et al. Lossof-function and residual channel activity of connexin26 mutations associated with non-syndromic deafness. FEBS Lett. 2003; 533: 79-88.

26. Kudo T, Ikeda K, Oshima T, Kure S, Tammasaeng M, Prasansuk S, et al. GJB2 (connexin 26) mutations and childhood deafness in Thailand. Neutrotol. $2001 ; 22: 858-861$.

27. Pandya A, Arnos KS, Xia XJ, Welch KO, Blanton SH, Friedman TB, et al. Frequency and distribution of G]B2 (connexin 26) and G]B6 (connexin 30) mutations in a large North American repositOly of deaf probands. Genet Med. 2003; 5: 295-303.

28. Erkoc MA, Tufan T, Comertpay G, Yilmaz MB, Alptekin D. P.[V27i; E114g] Compound Heterozygous State in Gjb2 Gene Could Be an Indicator of the Severity of Congenital Hearing Loss. Otolaryngology. 2015; 5: 10-12.

29. Choi Soo-Young et al. Functional Evaluation of GJB2 Variants in Nonsyndromic Hearing Loss. Mol Med. 2011; 17 : 1. 